Scientia studia, São Paulo, v. 11, n. 3, p. 137-67, 2013

\title{
sit \\ Warren Weaver y el Programa de Biología Experimental de la Fundación Rockefeller
}

\author{
Francisco Javier Serrano-Bosquet \\ Gustavo Gaponi
}

\begin{abstract}
$\ddot{\sim}$
RESUMEN

El objetivo de este trabajo es poner al descubierto los principales valores cognitivos y epistemológicos desde los que Warren Weaver puso en marcha el Programa de Biología Experimental, un programa que llevado a cabo desde la presidencia de la división de ciencias naturales de la Fundación Rockefeller, marcó y condicionó en buena medida el posterior desarrollo de la investigación biológica. Para tal fin se mostrará, en primer lugar, cómo fue la llegada de Weaver a la Fundación Rockefeller, así como las razones bajo las cuáles el consejo de esa institución decidió entre 1932 y 1933 dar prioridad a las investigaciones biomédicas, y la manera por la cual lo hicieron. En un segundo momento, el más extenso e importante, veremos algunos de los elementos más significativos de la perspectiva epistemológica y cognoscitiva de de Weaver. Finalizaremos viendo cómo esa perspectiva, desarrollada en conexión con el Programa de Biología Experimental, inter-actuó con la visión reduccionista de la biología a la que el programa parecía apuntar.
\end{abstract}

Palabras-GLAVE • Weaver. Fundación Rockefeller. Biología experimental. Biología molecular.

Reduccionismo. Valores cognitivos. Epistemología.

\section{INTRODUGGIÓN}

Cuando en 1932 Warren Weaver fue invitado por el entonces presidente de la Fundación Rockefeller, Max Mason, a formar parte de su equipo de trabajo, muy pocos podrían haber sospechado hasta dónde llegaría este joven matemático e ingeniero a influir en el desarrollo de las ciencias de la vida. Con el dinero de la Fundación Rockefeller equipó numerosos laboratorios, financió universidades y carreras, supo atraer la atención de jóvenes científicos de distintas áreas y puso en marcha numerosos proyectos interdisciplinarios de investigación. Pero mucho más importante que todo ello fue la contribución que hizo al nacimiento de una nueva biología experimental cuya mayor expresión encontramos en la biología molecular, una nueva forma de biología experimental que, bajo su dirección adquirió no solamente forma, sino también nombre propio. 
La elección de Weaver no había sido casual. Mason había sido su profesor de matemáticas aplicadas en la Universidad de Wisconsin, así como mentor y amigo personal. Fruto de esa relación profesional y personal en 1929 publicaron El campo electromagnético (The electromagnetic field), un libro que muy pronto se convirtió en un clásico (cf. Rees, 1987, p. 496-7). Cuando Mason fue nombrado en 1931 presidente de la Fundación Rockefeller, pensó rápidamente en su protegido Weaver como el mejor sustituto en la dirección de la división de ciencias naturales de esta misma institución (cf. Glass, 1991, p. 305). Mason no sólo quería que ocupara su lugar alguien de plena confianza y capaz de continuar los proyectos que él mismo había comenzado, sino que también deseaba que sucesor estuviese preparado para darle nueva estructura y continuidad al programa de ciencias naturales bajo los nuevos principios dictados por el consejo de la fundación (cf. Weaver, 1959, p. 7).

Ello significaba que el candidato debía ser competente para, al menos, dos cosas: en primer lugar, para ayudar en la reorganización de la Fundación Rockefeller, de tal manera que esta absorbiera los objetivos y programas de muchas otras agencias Rockefeller que habían sido fundadas desde 1903 para propósitos especiales (cf. Weaver, 1964b, p. 223), y, en segundo lugar, debía llevar la división de ciencias naturales más allá de donde había llegado con sus programas de medicina y salud pública. El consejo pedía, en su intento por impulsar las ciencias naturales, las ciencias sociales y las humanidades (cf. Rusk, 1959, p. 3), que la división de ciencias naturales adquiriera nuevos y más profundos compromisos.

Pero, ¿por qué éste cambio? ¿Bajo qué perspectiva? ¿Con qué fines? ¿De qué manera la división de ciencias naturales podía ayudar en el desarrollo de las ciencias sociales y las humanidades? Y ante todo, ¿porqué por impulso de las ciencias naturales entendieron principalmente promover las ciencias de la vida (biología, agronomía y virología principalmente)? Las respuestas a estas cuestiones las vamos a poder encontrar en publicaciones e informes del mismo Weaver, aunque eso no signifique que él siguiese al pie de la letra, o compartiera completamente, todos los principios marcados por el consejo de la fundación.

En las numerosas ocasiones y textos en los que Weaver ofreció una radiografía de los valores y principios epistémicos que desde ese organismo se intentaba imponer, podemos ver que, en general, él los aceptaba: aunque no siempre. Y había punto crucial en el que la coincidencia era particularmente clara y definitiva: tanto para Weaver como para el consejo, el éxito de los programas dependerían, en buena medida, de la libertad de la que debían disfrutar los principales protagonistas de cada unos de los proyectos de investigación. Ambas partes, el consejo y Weaver, consideran esencial que los responsables de cada proyecto pudieran tomar decisiones libremente en función de las oportunidades que fueran apareciendo, sin sentirse encorsetados en diseños pre- 
vios (cf. 1959, p. 7). YWeaver fue el primero en darse y en ejercer esa libertad: por eso, más allá de las instrucciones generales dadas por el consejo, la división de ciencias naturales de la Fundación Rockefeller fue, entre 1933 y 1958, un reflejo cada vez más claro de su propia concepción de ciencia.

Una concepción que debe ser estudiada no sólo a partir del análisis de los distintos intereses y valores sociales, políticos e ideológicos de Weaver y de la fundación, sino principalmente desde los valores cognitivos, siguiendo a Hugh Lacey (2008), sobre los que el ingeniero de Wisconsin puso en marcha los principales proyectos y programas de investigación que se desarrollaron bajo su dirección. No negamos con ello la extraordinaria importancia y pertinencia de un posible estudio sobre el papel que los valores sociales juegan, desde la perspectiva de Weaver, en el desarrollo de la investigación científica, y mucho menos el que esta (la actividad científica) jugó dentro del proceso civilizatorio y los planes expansionistas que promovieron tanto la Fundación Rockefeller como del gobierno de los Estados Unidos. Sin embargo, en esta ocasión vamos a centrarnos en el análisis de la perspectiva epistemológica o cognoscitiva de Weaver.

Para nuestro propósito contamos con, y nos apoyaremos principalmente en, numerosos escritos del mismo Warren Weaver. Trabajos, tanto formales como divulgativos, en los que da a conocer de manera relativamente clara y sencilla su concepción de ciencia. Ejemplos de ello los tenemos en los siguientes artículos de Weaver: "Ciencia e imaginación" (1929); "El reino de la probabilidad" (1930); "Ciencia y complejidad" (1948); "Las imperfecciones de la ciencia" (1960); "Un cuarto de siglo en las ciencias naturales" (1961b); "Explicación científica" (1964a); y "Confesiones de un científico humanista” (1966).

Textos todos ellos que, en conjunto, nos permiten no sólo conocer su concepción de ciencia, sino también ver la evolución de su pensamiento. Un claro ejemplo de este proceso lo tenemos al comparar los textos de Weaver sobre el reino de la probabilidad (1930) y el de la relación entre la ciencia y la complejidad (1948). Si en el primero de ellos aventuraba Weaver que el siglo xx - o al menos su primera mitad - sería conocido como el "reino de la probabilidad" (1930, p. 466), el segundo ya era una apuesta clara y constante por la superación de ese abordaje de la complejidad organizada. Ésta, acabó pensando Weaver (cf. 1948, p. 539) planteaba problemas que, como veremos, no podían ser resueltos con instrumentos y metodologías probabilísticas o estadísticas. Pero, más allá de estas y otras diferencias entre unos textos y otros, es posible identificar en ellos unos principios básicos que permanecieron constantes y, en buena medida, acabaron incidiendo en los proyectos de investigación biológica que bajo su dirección se llevaron a cabo en la Fundación Rockefeller. 


\section{Dos FoRMAS DE EXPLIGAGIÓN CIENTÍFICA}

“¿Qué es la ciencia? ¿Qué no es la ciencia? ¿Qué se puede esperar de ella? ¿Qué tipo de problemas nos puede ayudar a resolver?", se pregunta Weaver (1948, p. 542). La ciencia, continúa, ha hecho progresos notables en la gran tarea de solucionar problemas lógicos y cuantitativos. Sus éxitos han sido numerosos y llamativos, pero no puede resolverlos todos. Tan sólo puede ayudarnos a solucionar aquellos en los que los factores predominantes están sujetos a las leyes básicas de la lógica y son en su mayor parte medibles (cf. 194.8, p. 542-3). Para Weaver, el lenguaje lógico y matemático, tanto cuanto la medición, ocupan un lugar central en la ciencia ¿Significa ello que nos encontramos con una concepción puramente formalista de la ciencia? La cuestión no es tan sencilla.

Al tratar de las imperfecciones de la ciencia, Weaver se pregunta: ¿qué es lo que realmente quiere un científico cuando se enfrenta ante cualquier objeto o fenómeno natural? "Tiene un deseo profundo de comprender" (1960, p. 421). Ahora bien, ¿qué significa para Weaver comprender? ¿Y explicar? Esta es una cuestión recurrente en sus escritos. En todos ellos habla siempre de dos grandes formas de explicación o comprensión científica. En su trabajo de 1964, Weaver recuerda cómo históricamente se han desarrollado principalmente dos grandes formas de explicación científica: la explicación horizontal y la explicación vertical (cf. 1964a, p. 1299). La primera de ellas, la más familiar, antigua y popular consiste en la explicación de cualquier objeto o fenómeno desconocido a partir de términos familiares (1964a, p. 1297). Es la forma de explicación que encontramos en los diccionarios, las metáforas y las analogías (1964a, p. 1297-8). Ahora bien - advierte Weaver (cf. 196o, p. 422; 1964a, p. 1298) - esa forma de explicación debe ser descartada automáticamente como una forma válida de explicación científica, ya que no puede ofrecer una verdadera comprensión (científica) de ningún fenómeno en estudio: "lógica y filosóficamente son un fraude" (1960, p. 4.22). Lo único que se consigue - continúa - intentando explicar o comprender lo desconocido en términos conocidos o familiares es desvanecer la curiosidad.

La segunda forma de explicación, la vertical, es aquella en la que no hay ningún tipo de preocupación por la familiaridad. Por el contrario, los términos en los que son descritos los fenómenos son cada vez menos familiares, más básicos y abstractos, que los fenómenos mismos que se están explicando (cf. 1964a, p. 1298). Esta forma de explicación consiste, principalmente, en intentar explicar un fenómeno u objeto por medio de deducciones. Es decir, a partir de unos primeros principios, de una primera verdad o verdades incuestionables, se intenta reconstruir todo el fenómeno. Pero, ¿de dónde obtenemos esa primera verdad, esos primeros principios? Un científico, señala Weaver, podría en principio buscar por medio de la abstracción y la lógica aquellos primeros principios, aquellas primeras sentencias o axiomas tan obviamente ciertas, 
claramente necesarias y patentes, que él pudiera considerar que todos los hombres razonables aceptarían sin ningún tipo de examen. Pero, si bien este tipo de respuesta pareció satisfactoria durante muchos siglos, la historia reciente de la ciencia nos ha obligado a descartarla (cf. 1964a, p. 1298). En una obra anterior, muy temprana, él mismo ya había dado ejemplo histórico, muy claro, de ese parecer (cf. 1929).

En Los elementos de Euclides, según Weaver, podemos ver cómo los griegos reconocían claramente que la matemática, como una estructura lógica que era, debía comenzar por alguna parte, por alguna serie de principios, elementos o axiomas, de tal manera que sus posteriores argumentaciones no fueran más que un desarrollo y una extensión lógica de los primeros. Los elementos básicos, concretos, de los que partía la matemática (la geometría, en el caso) eran el punto, la línea, la línea recta, etc. Entidades bien conocidas y tan firmemente reconocidas que no necesitaban una gran explicación o descripción (cf. 1929, p. 426). Ahora bien, para Weaver, las llamadas "definiciones" de Los elementos eran, si queremos ser rigurosos, vagas e informales. Su verdadero propósito (el de las definiciones) era simplemente identificar los conceptos que estaban en la mente del escritor con los conceptos que se supone que tiene el lector. Los axiomas eran presentados como declaraciones ya aceptadas sobre elementos familiares.

Por ello no debe sorprender que la vieja creencia de que los postulados de Euclides eran verdades evidentes por sí mismas, o que era posible probar la verdad de los menos evidentes a partir de los más evidentes, fuera completamente destruida antes o después. Eso es algo que ocurrió en el siglo xix con los trabajos independientes de Lobachefski y Bolyai. Ambos demostraron que era posible alterar los postulados presentados por Euclides y derivar lógicamente de los mismos nuevos cuerpos de doctrina. Ejemplo de eso son las geometrías no euclidianas que ellos mismos desarrollaron. Recuerde se que el desarrollo de esas geometrías no resultó baladí. Por el contrario, ellas jugaron un papel central en la articulación de teorías científicas tan importantes como la teoría de la relatividad (cf. Weaver, 1929, p. 427).

Pero eso introducía, para Weaver, un enorme problema dentro del corazón mismo de la ciencia, pues era ahora evidente la imposibilidad de encontrar unos primeros principios universales, comunes para todos y en todo momento. Por consiguiente, los postulados o declaraciones de los que había que partir dependían del fenómeno o problema a tratar en cada caso. Incluso, dos matemáticos podían perfectamente asumir dos conjuntos muy diferentes de postulados - aun cuando estuviesen trabajando sobre el mismo fenómeno - y, aplicando procedimientos lógicos llegar, paulatinamente, a niveles de explicación cada vez de mayor complejidad (cf. 1964a, p. 1299).

Ahora bien, se pregunta Weaver (1964a, p. 1300), ¿qué significa realmente esto? ¿Qué implicaciones tiene en nuestras formas y posibilidades de conocimiento? El he- 
cho de que el matemático sea libre a la hora de elegir la base de postulados significa que ninguno de los dos modelos explicativos, ni el horizontal ni el vertical, es definitivo y completo. Siempre son relativos y limitados, ya que el punto de partida es establecido arbitrariamente y se encuentra condicionado por un antropocentrismo del que no podemos escapar. Eso, insiste Weaver (cf. 1929, p. 427-8), debería provocar entre los científicos una nueva actitud hacia los principios de las matemáticas. Una actitud que podemos resumir en los siguientes puntos:

(1) El hecho de que el carácter axiomático (y no axiomático) de la matemática moderna rompa por completo con la supuesta conexión previa entre las matemáticas y la verdad, debía producir -y produjo según Weaver entre algunos matemáticos- una actitud menos pretenciosa pero de mayor consistencia lógica. Los matemáticos ni siquiera entienden ya la pregunta “¿Es cierta esta afirmación?” sino que concentran sus energías exclusivamente en atacar, con gran rigor, la pregunta “ ¿Es esta afirmación tautológica?"

(2) La toma de conciencia de la inexistencia de una definición última y definitiva de elementos debe obligar a ver que la teoría no es sólo una teoría acerca de las cosas particulares que se comportan de una manera determinada, sino más bien una teoría general sobre todas las cosas que se comportan de esta manera.

Así, para Weaver, podríamos coincidir con Bertrand Russell cuando define las matemáticas como aquella asignatura en la que nunca sabemos de lo que estamos hablando, o si lo que estamos diciendo es verdad (cf. 1929, p. 428). En ese sentido, el carácter supuestamente axiomático de las matemáticas modernas deja claro que un matemático no es un descubridor, sino un creador. Pero, si las matemáticas han de ser consideradas como una disciplina cercana al arte en cuanto a su naturaleza más creativa que descubridora, ¿qué ocurre con la física? Si esta es una ciencia eminentemente cuantitativa preocupada tan sólo por aquello que se puede medir, es evidente que, aquello que se diga de las matemáticas, vale también para cualquier teoría física. Máxime cuando hablamos de física teórica, que no es más que la explicación de resultados experimentales. Es decir, no es ni más ni menos que un cuerpo de doctrinas matemáticas (cf. 1929, p. 431).

De ahí, sostiene Weaver (1964a, p. 1299) que el formalismo matemático (versión actual de la explicación vertical vista antes) que hoy en día caracteriza la física teórica moderna, lleve a los científicos a sostener "que un fenómeno se entiende cuando se posee una teoría satisfactoria para dicho fenómeno”. Es decir, cuando se posee un 
cuerpo de ecuaciones matemáticas que dan cuenta del estado de interdependencia de cantidades o variables representadas simplemente por letras en las ecuaciones (cf. 1960, p. 421); y junto a este cuerpo de ecuaciones hay un juego de reglas y procesos tanto experimentales como de sustitución de variables. Empero, ¿en qué sentido todo este proceso nos ayuda realmente en la comprensión del fenómeno?

Las ecuaciones y las teorías son una suerte de "caja negra" que puede ser alimentada con un juego de números y, tras ser "puesta en marcha", se obtiene un nuevo juego de números. Si este segundo juego de números se corresponde con los obtenidos tras la observación reglada de un determinado fenómeno natural, entonces tenemos una teoría exitosa. En ese caso, dice sarcásticamente Weaver que debemos "aceptar el resultado, ser agradecidos, y no ir más lejos con nuestras preguntas" (1960, p. 4,22), es decir, no debemos insistir en preguntas sobre el significado físico de las variables y cantidades; y es por eso que dicho modo de proceder tampoco puede ser considerado como una forma válida de comprensión. Bajo ese enfoque los científicos no se preguntan por la naturaleza real del fenómeno físico. De hecho, el proceso formal reconocetal y como se pone manifiesto en la moderna mecánica cuántica - que "es imposible comprender un fenómeno, y es absurdo intentarlo. Todo lo que se puede hacer, y esto es un triunfo de grandes dimensiones, es 'comercializar' exitosamente con el fenómeno" (1960, p. 422).

\section{LAS LIMITAGiONES DE LA GIENGIA}

Pero, si la ciencia no puede darnos una explicación propiamente dicha de los fenómenos, sino sólo nos aporta una serie de instrumentos que nos permiten ver la relación existente entre variables y cantidades, de las que además no conseguimos consensuar su significado físico, ¿de dónde proviene entonces el prestigio de la ciencia? ¿Cuáles son los criterios que nos permiten o ayudan a elegir entre diferentes teorías? ¿Qué hace a una teoría especial? Cuando decimos que una teoría es exitosa, ¿qué queremos decir realmente? Para Weaver, simplemente que es general, elegante y tiene un gran poder de control y predicción (cf. 1960, p. 423). Nuestra pequeña y ordenada caja negra es general si funciona para un gran número de problemas y puede ser aplicada de manera progresiva dando cuenta de numerosos fenómenos y casos; y es elegante si es simple y está bien organizada. Pero lo más importante es que ella nos permita controlar el cambio de unas variables a partir de la manipulación de otras, teniendo así gran capacidad y éxito de predicción.

En esa caracterización de las virtudes de una teoría no se hace alusión a su capacidad explicativa; porque, en realidad, no hay forma de explicar la naturaleza misma de 
las cosas (cf. 1960, p. 423).Y esto, según Weaver, valía para las dos formas de explicación más comunes de la ciencia: la horizontal y la vertical. Ninguna ofrece, en el sentido estricto de la palabra, una verdadera y completa explicación (cf. 1960, p. 423). Pero, además de esta importante limitación, ¿podemos encontrar alguna otra "imperfección" en la ciencia? La respuesta de Weaver (1960, p. 423), a este respecto, es contundente: al menos hay que señalar otras cuatro imperfecciones o limitaciones más. En realidad, Weaver (1960, p. 423) alude a otras cinco "imperfecciones". Sin embargo la primera que señala no es otra que esa incapacidad de la ciencia para dar una explicación última de los fenómenos, a la que ya hemos aludido.

Esas limitaciones son:

(1) Los mismos científicos no se ponen de acuerdo - como ya hemos avisado previamente - sobre los más profundos y centrales aspectos de la ciencia. De hecho, muchos de ellos - como es el caso de Albert Einstein - son reacios a aceptar el tipo abstracto de la "caja negra" descrito antes y reclaman, que una teoría no está completamente terminada hasta que no es clarificado el significado físico de todas y cada una de las variables y cantidades, ofreciéndose además explicaciones en términos causales y deterministas (1960, p. 424). Weaver tiene evidentemente en mente las discusiones producidas en el seno de la mecánica cuántica entre los "caballeros del continuo" y quienes apostaban por la llamada "interpretación de Copenhague".

(2) La ciencia que se ocupa de los fenómenos atómicos y sub-atómicos es, denuncia Weaver (1930), probabilística. Es decir, el conocimiento estricto y preciso es, en este nivel, imposible. Podemos saber cuál será el comportamiento promedio de una enorme cantidad de individuos, pero no el de uno concreto. Esto viene a poner en tela de juicio el determinismo que había distinguido y dominado hasta entonces la ciencia.

(3) La lógica, parte integral y central de la ciencia, no tiene ya la reputación que una vez mereció. Sus dos principales formas, la deductiva y la inductiva, se han mostrado inconsistentes y limitadas. En lo que atañe a la lógica deductiva, Weaver alude a los resultados de Gödel; y en lo que respecta a los problemas de la lógica inductiva, invoca a David Hume y a Nelson Goodman. Retomando las palabras de Kettering, podemos decir, según la advertencia de Weaver: "cuidado con la lógica. Es una forma organizada de ir al error con confianza" (1960, p. 425).

(4) La supuesta objetividad de la ciencia también carece de apoyo. Si ante cualquier fenómeno o evento natural hay (casi) siempre distintas explica- 
ciones científicas, ¿cómo o por qué elegimos finalmente una? Si es cierto, señala Weaver, que tendemos a aceptar aquellas explicaciones que parecen "más creíbles" u ofrecen "un criterio último de credibilidad", también es cierto que son muy variadas las razones que numerosos autores han dado para ser escépticos ante la supuesta objetividad de los "hechos científicos", punto en el que Weaver apela a las tesis de Polanyi (1958).

Resumiendo, no podemos negar las bondades y beneficios que la ciencia aporta, pero tampoco el desacuerdo aparentemente irresoluble que existe entre los mismos científicos sobre la relación que hay entre el pensamiento científico y la realidad, y entre la naturaleza y el significado de la realidad misma (cf. 1960, p. 426-7). Las explicaciones científicas son útiles, pero no dan una explicación sobria y rotunda. La antigua idea de inevitabilidad, de determinismo ha desaparecido; y la ciencia, al menos a nivel sub-atómico, se ha tornado estadística, azarosa. La lógica, considerada hasta ahora infalible e irrefutable, es en realidad débil e incompleta. La idea de verdad o de ciencia objetiva es tan sólo una brizna de nuestra voluntad.

La ciencia - dice Weaver recordando a Popper - no es un sistema de declaraciones ciertas o bien establecidas, como tampoco es un sistema que de manera constante avance hacia un estado final de conocimiento (cf. 1960, p. 427). El antiguo ideal científico de un conocimiento absolutamente seguro y demostrable, nos dice, ha resultado ser un ídolo; y la demanda de objetividad científica hace inevitable que todo enunciado científico deba ser considerado siempre provisional. Dichos enunciados pueden ser corroborados; pero cada corroboración es relativa a otros enunciados que, de nuevo, deben ser considerados provisionales. La base empírica de la ciencia objetiva no tiene nada de "absoluta" en sí. Simplemente nos detenemos en un momento de nuestras demostraciones cuando estamos satisfechos, cuando consideramos que, los pilares sobre los que se levanta nuestro edificio, son suficientemente firmes como para empezar a levantar, al menos por el momento, la estructura.

Pero, lejos de considerar estas limitaciones como algo perjudicial, Weaver afirma que las mismas deben ser vistas como algo que hace de la ciencia algo más entrañable. La ciencia, señala, debe ser vista como una empresa y como un producto humano, como un producto histórico y cultural:

La ciencia busca el orden creciente pero no pretende ocuparse de una verdad inmutable. Magnífica como ciencia, y magníficamente útil como son sus aplicaciones, sabemos que su aparente objetividad es solamente superficial; sus declaraciones están siempre abiertas a revisión. Sabemos que, como todo arte, es una cuestión cultural (Weaver, 1966, p. 15). 
No debemos olvidar que a Weaver le gustaba de subrayar que la ciencia aporta la base de conocimientos sobre los que se fundamentan procesos y programas industriales que hacen nuestra vida más sana, más cómoda, más segura y agradable (cf. 1961a, p. 65-7). De su desarrollo, salud y vigor depende el crecimiento económico de los países, pero también su defensa y prestigio internacional (p. 67-8). Por otro lado, sólo la ciencia, aunque lo haga sólo en parte, es capaz de revelar el orden y la belleza del universo (p. 69). Pero, tal vez, el mayor aporte de la ciencia, pensaba Weaver, estaba aún por hacerse. Se trataba de su papel en el proceso de unificación de la vida humana.

\section{LA GIENGIA GOMO BÚSQUEDA DE UNA UNIDAD SUBYAGENTE}

¿Qué quiere decir Weaver por "unificación de la vida humana"? ¿Cómo es posible, si es que lo es, llegar a alcanzarla? Y, caso de la que respuesta sea afirmativa, ¿es deseable, oportuna o pertinente? Como hemos señalado previamente, no es nuestro objetivo detenernos por ahora en el análisis exhaustivo de los valores sociales que pudieran estar en juego. Sin embargo, es necesario hacer referencia a este punto porque constituye el último peldaño de la visión histórico-epistemológica que pautó la labor de Weaver como estratega de la investigación científica.

La historia de la ciencia, según la considera Weaver, es la historia de una obsesión por encontrar aquellos principios que nos permitan dar cuenta de la existencia de una unidad subyacente a la multiplicidad de fenómenos con los que nos ponen en contacto nuestros sentidos (cf. 1959; 1966). La historia de la ciencia es una marcha hacia un orden creciente fundado en principios unificadores cada vez más amplios. Principios esos que no sólo encontramos en los fenómenos naturales, sino también en la pluralidad de fenómenos y manifestaciones culturales. Con un lenguaje que recuerda en numerosas ocasiones al Timeo de Platón, o El ensayador de Galileo, Weaver señala que la historia de la ciencia es la historia de cómo el ser humano ha ido paulatinamente descubriendo una realidad cada vez más compleja y cómo, paralelamente, ha ido haciendo cada vez mayores esfuerzos por encontrar principios más unificadores:

A lo largo de la historia, la ciencia ha ido poniendo al descubierto un mundo cada vez más y más complejo: pero al mismo tiempo ha tenido éxito en el descubrimiento de más y más principios unificadores que dan cuenta de una variedad cada vez mayor que permite reconocer una unidad subyacente. El ser humano, en definitiva, ha descubierto los muchos y el uno (1966, p. 13). 
Detrás de la imagen aparentemente compleja, a veces caótica, del mundo que nos ofrecen nuestros sentidos, hay un orden, una unidad última que da cuenta de todo. Y en lo que respecta al esfuerzo por comprender esa unidad subyacente, las ciencias físicas se han mostrado más eficaces, a pesar de sus limitaciones, que cualquier otro emprendimiento cognitivo. Por lo tanto, advierte y señala Weaver (cf. 1966, p. 15), cualquier intento por comprender y, finalmente, por predecir y controlar todo tipo de proceso, ya sea natural o social, sólo será posible a partir del desarrollo inicial de programas que partan de unidades de explicación básicas cada vez más y más generales, y de conceptos cada vez más abstractos, que permitan no sólo la unificación, sino también la universalización y el control de procesos y variables (cf. 1959, p. 43). Y la biología no podía hurtarse a ese vector de progreso que unificaba todo el desarrollo de la ciencia.

En ese sentido, consideraba Weaver, sólo será posible hablar de una verdadera biología científica, experimental, a partir de programas que permitiesen dar el paso explicativo de la materia inanimada a la vida: a partir de de programas y proyectos que nos ayudasen a superar la brecha aparentemente existente entre el mundo inanimado y el mundo vivo. En definitiva, el principal camino del progreso para las ciencias de la vida, debía ser el desarrollo de programas y proyectos de investigación que, teniendo como base los métodos de explicación e investigación provenientes de las ciencias físicas, nos permitan hacernos cargo de los problemas de complejidad organizada de las ciencias sociales y biológicas. Y ese va a ser el gran proyecto al que va a dirigir sus esfuerzos la Fundación Rockefeller la dirección de Weaver.

Pero, ¿qué quiere decir Warren Weaver con "problemas de complejidad organizada"? ¿Por qué dice que los problemas típicos de las ciencias biológicas y sociales son de "complejidad organizada"? ¿Por qué no ocurre lo mismo con los de las ciencias físicas? ¿Por qué esta distinción es importante a la hora de hablar de la superación de la brecha aparentemente existente entre el mundo inanimado y el mundo vivo? Para poder responder a estas preguntas es fundamental tener presente la tipificación de los problemas científicos que Weaver hace a partir de las categorías de grado y tipo de complejidad. La misma fue reiterada en el balance de 25 años en las ciencias naturales (1959; 1961b), pero ya había sido claramente delineada en el ensayo sobre ciencia y complexidad (1948). En ambos artículos, Weaver (1948, p. 536) afirma que la historia de la ciencia, sobre todo en los últimos 300 años, es la historia del descubrimiento de tres tipos fundamentales de problemas y, paralelamente, del desarrollo de distintas formas de respuesta para los mismos:

(1) problemas de simplicidad;

(2) problemas de complejidad desorganizada; y

(3) problemas de complejidad organizada. 


\section{DE LA SIMPLICIDAD A LA COMPLEJIDAD ORGANIZADA}

La diversidad que percibimos normalmente, sostenía Weaver (1966, p. 13), no es sino un fenómeno superficial. Cuando uno mira con mayor profundidad, cuando uno observa con atención los fenómenos, la unidad universal se vuelve aparente (1966, p. 14). De ahí que el objetivo principal de la ciencia sea poner al descubierto la unidad o unidades últimas que se esconden detrás de los complejos fenómenos aparentes, y que la historia de la ciencia sea la historia por la búsqueda de la unidad, por encontrar aquella ley o leyes que dan cuenta finalmente de toda la complejidad aparente que los fenómenos parecen mostrar. Detrás de toda la complejidad aparente del mundo, tanto físico como biológico, hay una serie de leyes o principios últimos.

Ahora bien, ¿cómo dar cuenta de esa unidad, de esos primeros principios que se esconden detrás de lo aparente? Dejando atrás, responde Weaver (1961b), como ya se hizo entre los siglos xVII y xIx, la visión aristotélica, esencialista, organicista, teleológica y de movimientos inmanentes, adoptando un nuevo modelo mecanicista y matematizado, donde la experiencia tenga un papel más de verificación que genético. Sólo bajo esa perspectiva mecanicista fue posible, nos recuerda Weaver, llevar a cabo la búsqueda de patrones, de regularidades y de simetrías. Unos patrones, primero geométricos, más adelante conductuales, bajo los cuales se fue forjando (y podemos sustentar hoy en día) una concepción de la causalidad inmediata, por contacto directo, que permitía defender una explicación del mundo (y de cualquier sistema) que fuese de la parte al todo. Tomando como ejemplo el reloj, podía entenderse el conocimiento del todo a partir del conocimiento de las partes. Eso significaba que el todo, el sistema, estaría completamente explicado sólo cuando fuese posible ir dando cuenta del proceso lineal, de la transición (por ejemplo, del movimiento mecánico) de una parte del sistema a otro (cf. 1961b, p. 57).

Durante trescientos años, las ciencias físicas desarrollaron métodos, formulas y técnicas experimentales y analíticas que permitieron manejar cada vez con mayor facilidad problemas de pocas variables. Por ejemplo, problemas relativos a la relación entre la presión, el volumen y la temperatura de un gas. El carácter esencial de este tipo de problemas está en el hecho de que una variable depende enteramente de la segunda y no de una gran cantidad de factores. En otras palabras, el comportamiento de la primera variable se puede describir con un alto y útil grado de precisión teniendo en cuenta solamente su dependencia con la segunda (cf. 1961b, p. 57).

Estos problemas de dos variables son simples en su estructura: una simplicidad que resulta en gran medida del hecho de que las teorías o los experimentos necesitan tan sólo dar cuenta de dos variables, porque los cambios en una de ellas producen cambios en la otra (cf. 1961b, p. 57). Esto resultaba fundamental, ya que la restricción a dos 
variables, y en la mayoría de los casos a las relaciones simples entre las variables y sus derivadas primera y segunda, permitía mantener el sistema teórico en conformidad con la capacidad analítica y computacional de las matemáticas de la época.

Gracias a ello se produjeron importantes avances en el conocimiento de la naturaleza y en el desarrollo tecnológico. Pero, como señala Weaver, eso también limitó a la ciencia al estudio de fenómenos muy simples. Ello impidió que disciplinas como la biología o la medicina pudiesen desarrollarse como lo estaban haciendo las ciencias físicas (cf. 1959, p. 7-8). Las ciencias de la vida quedaron, entonces, prácticamente reducidas a la tarea de coleccionar, describir y clasificar. Y, según Weaver, esa situación sólo comenzó a revertirse a inicios del siglo xx, cuando empezaron los primeros intentos serios de cuantificación y de búsqueda sistemática de explicaciones físicas y químicas (cf. 1959, p. 9-10).

Por otro lado, también a inicios del siglo xx, pero quizá antes si se consideran los esfuerzos llevados a cabo por autores como Josiah Willard Gibbs, algunos matemáticos y físicos comenzaron a delinear un nuevo tipo de comprensión de la naturaleza. Se pretendía "desarrollar métodos analíticos desde los que fuera posible hacer frente a dos mil millones de variables", en vez de los dos o tres que se contemplaban hasta entonces. Para ello se desarrollaron técnicas de teoría de la probabilidad y de mecánica estadística que permitieron empezar a dar respuesta a problemas de complejidad desorganizada (Weaver, 1948, p. 537). Es decir, problemas que contienen un número de variables muy grande con un comportamiento individualmente errático e, incluso, desconocido. Sin embargo, y a pesar del desconocimiento del comportamiento individual de cada variable, el sistema posee cierto orden y propiedades promedias ordenables y analizables como un todo (cf. 1959, p. 11). Ejemplos de este tipo de problemas los tenemos al intentar determinar el movimiento de átomos o estrellas, descubrir las leyes fundamentales de la termodinámica, la herencia, el conocimiento o la comunicación e información (Weaver, 1959, p. 12-3).

Pero eso no es todo: hay otro tipo de problemas. Hay problemas que se encuentran en una región intermedia: entre los problemas de simplicidad y los problemas de complejidad desorganizada. No son problemas simples sino propios de sistemas muy complejos, pero ante los cuáles no caben técnicas o metodologías estadísticas o probabilísticas, ya que se dan procedimientos simultáneos de un gran número de variables y de factores interrelacionados en un todo orgánico. Se trata de problemas de complejidad organizada. Ejemplos de este tipo de problemas los encontramos cuando intentamos responder a preguntas como: ¿De qué depende el precio del pan? ¿Cómo es posible estabilizar la moneda? o ¿Cómo podemos explicar el patrón de comportamiento de un determinado grupo de personas? (cf. Weaver, 1959, p. 13-5). 
Son problemas complejos todos, desde luego, pero ante los que la estadística y la probabilidad resultan insuficientes. A ello hay que sumar el hecho, según Weaver, de que la mera descripción de objetos o eventos que participan en un fenómeno natural no puede considerarse una verdadera explicación. Es necesario, por el contrario, reducir los términos de la explicación a niveles básicos, a niveles cada vez más y más generales, a conceptos más y más abstractos. Un nivel de explicación que permita lograr una mejora considerable de nuestra capacidad de predicción y aumento en la sensación de control (cf. Weaver, 1959, p. 422).

Así, bajo estas premisas y preconcepciones Weaver (194.8) puso en marcha, a través de la Fundación Rockefeller, toda una serie de programas de investigación que intentaban responder a la convicción de que el gran reto de la ciencia de los siguientes cincuenta años era, principalmente, aprender a lidiar con los problemas de complejidad organizada. Yya en 1948, él se mostraba muy satisfecho y optimista con los avances hasta entonces conseguidos (1948, p. 54,0). Él podía contarse, por otra parte, entre los principales responsables de ese progreso. Ejemplo de ello sería la aplicación exitosa de métodos experimentales cuantitativos y métodos de análisis matemáticos propios de las ciencias físicas, al campo de las ciencias biológicas, de la medicina, e incluso de las ciencias sociales. Los resultados - concedía - eran aún dispersos, pero altamente prometedores. Un éxito y unas buenas perspectivas que se debían en gran parte, gustara o no, a los avances y contribuciones hechas durante la Segunda Guerra Mundial. ${ }^{1}$

Ahora, tres años después de finalizar la guerra, indica Weaver que a diferencia de lo ocurrido durante la misma, es fundamental para el buen desarrollo de la ciencia la creación de una atmosfera de completa libertad intelectual (cf. 194.8, p. 541). La libertad, la competitividad, la pluralidad de miras y la creación de grupos interdisciplinarios (valores todos ellos propios de la identidad estadounidenses), así como el desarrollo y uso de grandes computadoras, serán claves, fundamentales para el avance en el manejo de problemas complejos, sobre todo en las ciencias biológicas y sociales (cf. 194.8, p. 542). Pero clave es también tener presente, como este ejemplo señala, que ya sea en tiempos de guerra o de paz los programas generales de investigación y los

\footnotetext{
1 Señala dos tipos fundamentales de contribución. Uno es el desarrollo de la computación electrónica. Durante la Segunda Grande Guerra se desarrollaron nuevos tipos de dispositivos de computación electrónica con una capacidad, velocidad y flexibilidad tan asombrosa, que podemos aventurar que serán de un enorme impacto para el desarrollo de la ciencia. Harán posible hacer frente a problemas que antes eran demasiado complicados, y, más importante, van a justificar e inspirar el desarrollo de nuevos métodos de análisis aplicables a estos nuevos problemas de complejidad organizada. Las otras contribuciones de la ciencia en guerra, vinieron por cuenta del desarrollo de equipos mixtos para el análisis y resolución de problemas científicos, técnicos y tecnológicos (cf. Weaver, 194.8, p. 540). Así como trabajaron los grupos de análisis de operaciones de tiempos de la guerra, es posible creer que los grandes avances que la ciencia puede y debe alcanzar en los próximos cincuenta años serán fruto en gran medida de los equipos mixtos de trabajo y el uso de grandes máquinas de computación flexibles y de alta velocidad.
} 
Warren Weaver y el Programa de Biología Experimental de la Fundación Rogkefeller

proyectos científicos concretos son pensados y desarrollados no sólo bajo criterios epistemológicos y metodológicos, pero también hay toda una serie de concepciones del mundo (social y natural), de valores, bienes e intereses que rodean y condicionan tanto la concepción de ciencia como la actividad científica misma.

\section{RUPTURAS Y GONTINUIDADES GON LA VISIÓN}

\section{BACONIANA Y GALILEANA DE LA GIENCIA}

Como hemos podido ir observando, el valor de la ciencia en general y de las teorías científicas en particular no está, para Weaver, tanto en su capacidad explicativa como en la capacidad de controlar y manipular variables. Consciente de la imposibilidad de encontrar una explicación última y definitiva de la realidad, o de los fenómenos, la ciencia tiene como fin, para él, el desarrollo de teorías y de complejos matemáticos que permitan el control de variables y, con ello, de los fenómenos tanto naturales como sociales. Eso no significa, desde luego, que la ciencia esté completamente alejada de la estructura de la realidad. Al contrario, la ciencia nos acerca paulatinamente a la estructura del mundo, a las unidades constitutivas últimas del universo. Es por ello que los programas de investigación deben partir, reitera constantemente Weaver (1948; 1961b; 1964a), de la idea de que el control y el poder de las teorías dependen de nuestra capacidad de reducir los fenómenos a sus unidades últimas. Es por ello que, en principio no encontramos un quiebre, una revolución respecto a la concepción baconiana o galileana de la ciencia.

El fin de esta última era igualmente desarrollar conocimientos teóricos que, junto al desarrollo técnico o tecnológico, permitiesen una constante mejora de las condiciones de vida humana. Ahora bien, encontramos una gran diferencia en el nivel del análisis y el grado y tipo de complejidad de los problemas a resolver: mientras la ciencia renacentista y moderna trató de resolver problemas relativamente sencillos de muy pocas variables, Weaver trató de poner en marcha un programa que permitiera dar cuenta de problemas de alta complejidad organizada. Frente al modelo mecanicista y determinista de la ciencia moderna, Weaver se hizo eco de la renuncia a la posibilidad de explicaciones causales y determinista que había introducido la mecánica cuántica. El reduccionismo ontológico y metodológico al que apuntaba llevaba consigo también una renuncia epistemológica a todo intento por alcanzar auténticas explicaciones. La ciencia, dirá Weaver (1964a, p.1298), ha quedado reducida al desarrollo de complejos modelos matemáticos que, como una caja negra, nos permite controlar los outputs a partir de los inputs. 
En cualquier caso, Weaver (1948; 1961b) comparte con Galileo la idea de que la clave está en el desarrollo de complejos modelos matemáticos, aliados con la práctica técnica y experimental. Es fundamental el desarrollo de teorías junto al desarrollo tecnológico, pero también es importante la puesta en marcha inmediata de experimentos con los que se ponga a prueba la efectividad, el poder y el control del mecanismo. Ejemplo de ello, de cómo las teorías científicas debían ser y eran puestas a prueba inmediatamente, lo encontramos en los proyectos de investigación que se llevaron a cabo bajo el paraguas del Programa de Biología Experimental.

\section{El PROGRAMA DE BIOLOGÍA EXPERIMENTAL}

¿En qué consistió el Programa de Biología Experimental? ¿Cuáles fueron sus principales características, líneas de desarrollo y supuestos epistemológicos y cognitivos sobre los cuáles se levantó? ¿Qué buscaban realmente la Fundación Rockefeller y Warren Weaver con el mismo? ¿Cuáles fueron las principales aportaciones científicas que desde el mismo se hizo? Para responder esas cuestiones es importante saber que este programa fue el resultado de la solicitud hecha por el consejo de la Fundación Rockefeller en 1932, de dar a la fundación un importante giro hacia las ciencias de la vida. Un giro que, en término de Dean Rusk (1959, p. 4) ${ }^{2}$ se viese materializado en un programa de biología experimental que permitiese:

(1) Mejorar la comprensión del ser humano, cuyo bienestar debía ser uno de los principales principios guía de toda la innovación.

(2) Darle continuidad a los programas de medicina y salud pública desarrollados hasta ese momento.

(3) Erigir a la Fundación Rockefeller en uno de los principales protagonistas de la revolución que las ciencias de la vida estaban a punto de vivir. (4) Revertir la poca atención, interés y apoyo que - hasta entonces - las ciencias biológicas merecían a pesar de su extraordinaria importancia y su potencial práctico e intelectual.

2 En 1958, Dean Rusk era Presidente de la Fundación Rockefeller, puesto que ejerció entre 1952 (desde 1950 era fideicomisario de la misma institución) y enero de 1961, fecha en la que asumió el cargo de secretario de estado de los Estados Unidos. 
Esos objetivos se plasmaron en un programa que, llamado inicialmente Processos Vitales (Vital Processes) y, posteriormente, Programa de Biologia Experimental, tenía como uno de sus principales objetivos aplicar las herramientas y técnicas de las ciencias físicas a la resolución de problemas de las ciencias biológicas. Bajo esta perspectiva quedaron recogidos un gran número de proyectos de la División de Ciencias Naturales que, independientemente de la disciplina bajo la cual se desarrollaran, hacían finalmente énfasis en problemas biológicos. Encontramos así programas de fisiología, psicología, histología, genética, biología celular, bioquímica, embriología, ecología o biofísica. Pero también de medicina, agronomía, virología o matemáticas, en los que sus protagonistas mostraron un especial interés por la exploración de fenómenos relativos a sistemas vivos (cf. 1959, p. 25).

La idea central sobre la cual germinó y posteriormente se desarrolló el Programa de Biología Experimental era aquella según la cual todo fenómeno o problema biológico era un problema de complejidad organizada. Esta nueva imagen de la biología chocaba frontalmente con la visión centenaria denunciada por Weaver (cf. 1959, p. 121) que consideraba los fenómenos vitales como hechos inaccesibles e inabarcables por medio de auténticas investigaciones científicas. Considerados fenómenos erráticos, irracionales y excesivamente complejos, se presentan, bajo esta óptica, ante la ciencia de manera oscura y amenazante frente al orden, la regularidad, la simetría y la belleza que presenta la naturaleza física. El consejo de la Fundación Rockefellery Weaver (1948; 1961b) coincidían al afirmar, primero, que esta visión debía cambiar y que, de hecho, estaba ya cambiando. En segundo lugar, concordaban al señalar como uno de los principales objetivos y compromisos de la Fundación Rockefeller participar y colaborar en la aceleración de este cambio.

Durante siglos la investigación biológica había comenzado - y se había quedado casi siempre - en los niveles de observación, descripción y clasificación (cf. Weaver, 1959, p. 39). Sin embargo, un conjunto de circunstancias habían puesto en marcha y fomentado un cambio de actitud en muchos científicos hacia los fenómenos vivos. Una de las principales circunstancias o hechos que facilitaron este cambio de perspectiva fue la reflexión que en el seno de la ciencia empezó a darse, durante la primera mitad del siglo xx, sobre todo a partir del desarrollo de la mecánica cuántica y la teoría de la relatividad, en torno a la naturaleza, legitimidad y variedad de concepciones relativas al concepto de explicación científica. Esta revisión llevó, como señala Weaver (1964a), a reconocer la importancia que tiene para la ciencia y el conocimiento general, la identificación y comprensión de hechos superficiales de cualquier fenómeno a conocer. Sin embargo, y esta es una idea en la que Weaver (1948; 1964a) insiste en muchas ocasiones, el conocimiento de estos hechos externos no constituye una verdadera "expli- 
cación”. Es, para Weaver (1964a), de vital importancia analizar el fenómeno en los términos más fundamentales y universales que se pueda. ${ }^{3}$

Pero, ¿por qué esta insistencia de Weaver en torno a la necesidad de llevar a cabo análisis que partan de la identificación de los últimos términos, de las últimas unidades constitutivas de cada fenómeno? La respuesta nos la da el mismo Weaver (cf. 1959, p. 42) al señalar la necesidad de distinguir entre la noción ordinaria o popular de explicación y la noción de explicación científica. Una distinción que no es sino otra forma de referirse a la distinción ya vista anteriormente entre explicación horizontal y explicación vertical. ${ }^{4}$

Mientras la explicación ordinaria o popular vendría a coincidir con la explicación horizontal, es decir, vendrían a ser aquellos intentos de explicar lo desconocido a partir de lo conocido (cf. 1959, p. 42), la explicación científica vendría a hacer lo propio con la explicación vertical. Es decir, con aquel tipo de explicación que se da en términos abstractos, de la manera más universal y con los términos más compactos posibles. Pero, ¿no había señalado y reconocido ya el mismo Weaver (1959) las limitaciones de este modelo? Sí, pero tal y como hemos señalado también, Weaver (1960) reconoce que es en este nivel de explicación en el que se logra obtener la mayor capacidad predictiva y de control sobre las variables, dos de los valores fundamentales, centrales de su propuesta epistemológica.

En ese sentido, este tipo de explicación había dado buenos resultados en el ámbito de las ciencias físicas, pero ¿realmente era posible introducir, implementar y desarrollarlo exitosamente en el ámbito de las ciencias de la vida? No, reconoce Weaver (1961b, p. 60), mientras la biología se contente, como se había hecho hasta entonces, con técnicas, herramientas e instrumentos de investigación de gran escala de análisis. Los animales y las plantas, vistos desde niveles macroscópicos de análisis, presentan una complejidad y variedad tal, que se resisten a la unificación y simplificación que hacen posible una explicación satisfactoria. Es por ello necesario, reitera una y otra vez Weaver (1948; 1959; 1961b), generar un cambio de actitud en torno a las ciencias de la vida.

3 Weaver pone el ejemplo del fenómeno de la migración de las aves. Es fascinante - reconoce - trazar el itinerario exacto y la sincronización cuidadosa del chorlito dorado que se reproduce en el norte de Canadá y, después de un vuelo sin parar casi increíble sobre el agua, pasa los inviernos en las islas hawaianas. Sin embargo, el conocimiento de hechos externos no constituye una "explicación”. Cuando uno se da cuenta de que los animales que migran son aquellos que no poseen un buen mecanismo de ajuste de la temperatura, señala Weaver (1964a, p.1298), o que hay una relación entre el tiempo de salida y el ciclo de luz de la noche-día, entonces podemos decir que estamos empezando a "entender" un poco mejor.

4 Ya habíamos señalado anteriormente que Weaver (1929, p. 427-8) distinguió a lo largo de su carrera dos formas distintas de explicación. Si bien se refirió a cada una de ella de manera diferente en distintos textos, finalmente se trataba, a grandes rasgos, de las mismas definiciones y caracterizaciones. Aquí tenemos un buen ejemplo de ello. 
Una nueva actitud y forma de acercarse a los fenómenos biológicos desde la que sea posible demostrar que, a pesar de la complejidad y variedad que presentan los animales y las plantas, el mundo de los seres vivos exhibe una racionalidad, un orden y una belleza no muy lejanos a los que presenta el mundo físico. Para ello es necesario demostrar - y ese es uno de sus principales objetivos - que es posible pasar de la universalidad de la célula a la universalidad total de la molécula y del átomo alcanzando, de ese modo, un modelo de explicación en el nivel último de simplicidad y universalidad, de poder y control de procesos y variables. Pero, para ello, para poder llegar a este último nivel, se hace necesario, tal y como ya hemos señalado, desarrollar e implementar nuevas herramientas que, procedentes de la física y la química, permitan implementar nuevas formas de exploración, descripción y medida en biología (cf. Weaver, 1959, p. 43).

Este es el camino que eligió Weaver (1959) y siguió la Fundación Rockefeller a través principalmente del Programa de Biología Experimental. Un programa bajo el cual se invirtieron importantes recursos económicos, humanos e institucionales, con el fin de desarrollar y aplicar herramientas de las ciencias físicas en el ámbito de las ciencias de la vida, y demostrar, a su vez que eran tan efectivas en el mundo biológico como lo eran o habían sido en el puramente físico (cf. 1959, p. 122).5 Y eso significaba, en primer lugar, tal y como hemos estado viendo, llevar el análisis de los fenómenos hasta los niveles de escala más pequeños posibles. A poder ser, finalmente, hasta los niveles atómicos y moleculares.

El estudio de los componentes básicos de las estructuras orgánicas quedó así en el centro de la escena. Los más progresos sólidos del programa se dieron en torno a la elucidación de la estructura de importantes moléculas biológicas. Uno de los mejores ejemplos de la nueva actitud y perspectiva en torno a lo que debía entenderse por explicación científica, los niveles de análisis en los que debía darse esta y el papel que jugaba la pregunta por la estructura, lo encontramos en declaraciones como la siguiente: "El problema más básico o central de la biología moderna es el de descubrir la disposición detallada de los millones de átomos individuales dentro del ADN de los cromosomas" (Weaver, 1959, p. 47). Pero más allá del ADN y de otros casos particula-

5 Si el desarrollo de la ciencia, se dirá desde la Fundación Rockefeller, depende en buena medida de los desarrollos técnicos, tecnológicos y metodológicos desarrollados en física, la biología no podía ser una excepción. Máxime cuando no podemos si no reconocer que los fenómenos y problemas biológicos son tan difíciles e importantes, llega a reconocer Weaver (cf. 1959, p. 38), que nos vemos obligados a utilizar todos los recursos de los que se dispongan. Ahora bien, en ese sentido, hay que hacer notar que la influencia biología-física es mutua, se da en los dos sentidos. Esto se hace más evidente bajo dos rubros claves: separar y ver. Muchos de los desarrollos, señala Weaver, de técnicas físicas y químicas han ocurrido a partir de demandas de la biología. Ejemplo son los nuevos modelos de cromatógrafos y microscopios. 
res, hablar de estructura en biología es hablar ante todo de la estructura de las proteínas. Retomando la idea de Engstrom y Finean (1958, p. 101), Weaver afirmaba que

Las proteínas, como su nombre indica, son de primera importancia en la estructura de la materia viva. Ninguna célula podría vivir sin ellas, y cualquier discusión sobre la estructura biológica debe empezar necesariamente con la consideración de la estructura de las proteínas. (1959, p. 88)

\section{Las tres pringipales líneas del Programa de Biología Experimental}

Si analizamos en detalle los principales apoyos que bajo este programa se dieron, podremos ver cómo la gran mayoría de los recursos fueron destinados a proyectos vinculados con el descubrimiento, comprensión o funcionalidad de estructuras proteínicas, o con el desarrollo de metodologías, herramientas o instrumentos de separación y observación de las mismas. Ahora bien, ¿ello asegura que los proyectos puestos en marcha respondieron perfectamente a los objetivos y presuposiciones cognitivas y epistemológicas vistas? Si no es así, ¿en qué forma, medida o grado se consiguió? Para poder responder a esta cuestión se hace necesario distinguir y describir brevemente las tres principales líneas bajo las cuales, más allá del discurso o intenciones iniciales, se desarrolló realmente el programa.

Atendiendo a los números, a los apoyos dados por la Fundación Rockefeller al desarrollo de investigaciones biológicas entre 1933 y 1955, debemos distinguir en primer lugar el apoyo general que se dio desde la División de Ciencias Naturales, y el que se facilitó específicamente desde el Programa de Biología Experimental. Un primer análisis nos permite ver cómo, desde la división se apoyó programas, proyectos y grupos de investigación de naturalezas y perspectivas científicas muy diferentes. Encontramos así proyectos de investigación y programas de formación en oceanografía, primatología, paleontología, ${ }^{\mathbf{6}}$ y así un largo etcétera, alejados en principio de la visión de ciencia de Weaver.

Sin embargo, un análisis detenido de los números del Programa de Biología Experimental nos permite observar una mayor coincidencia inicial. Entre 1932 y 1959 la Fundación Rockefeller asignó 88.348.o93 de dólares en ayudas o apoyos al Programa

6 Valga como ejemplo de cada uno de ellos los programas de formación en oceanografía y biología de primates de la Universidad de Yale, y el programa de paleontología de la China Medical Board. Programas de formación y proyectos asociados desarrollados bajo concepciones y metodologías muy diferentes a las que Weaver intentó impulsar desde el Programa de Biología Experimental. 
de Biología Experimental. De estos, el 52,9\% (48.947.152 dólares) fueron destinados a proyectos y programas relacionados directamente con biología experimental, el 32, $4 \%$ a agricultura, el $5,5 \%$ a virología, el $4 \%$ a casos excepcionales y el $5,2 \%$ a gasto general (1959, p. 29). Aquí nos centraremos, como señalamos anteriormente, en las tres líneas más importantes: biología experimental, agronomía y virología.

\section{LA BIOLOGÍA EXPERIMENTAL}

Como acabamos de ver, los programas apoyados dentro del programa de biología experimental pertenecían a una importante variedad de disciplinas. El énfasis, el esfuerzo más fuerte se hizo, no obstante, en las interrelaciones entre la biología y la química, específicamente en las áreas de genética y fisiología. El mejor ejemplo de ello lo tenemos en el mismo reporte de gastos del Programa de Biología Experimental donde Weaver desglosa la forma en la que se invirtió, por áreas específicas, los 4.8.947.152 dólares del programa invertidos en biología experimental: el 22, $7 \%$ fue destinado a investigaciones propiamente biológicas (citología, ecología, embriología, histología, genética, microbiología, ${ }^{7}$ biología molecular y fisiología). El 21,8\% fue otorgado a proyectos de biología y química (bioquímica, química orgánica y química física), el 6,7\% a biología y física (biología de la radiación, estudios estructurales e instrumentación), el $1 \%$ a biología y matemáticas (biofísica, matemáticas y estadística) y el 47,8\% a soporte básico (cf. 1959, p. 32).

Ahora bien, a la hora de intentar comprender la filosofía organizativa y operativa de la Fundación y el programa de biología experimental, es importante comprender en cada caso la forma en la que, más allá de las áreas específicas, se organizó y distribuyeron los recursos y esfuerzos. En el caso de las investigaciones de biología experimental propiamente dicha una gran parte de la ayuda, el 62,5\%, se dedicó a ayudar directamente la investigación de científicos de universidades y laboratorios de todo el mundo. Más del 13,5\% a la formación de recursos humanos; y el 16,4\% a operaciones sobre el terreno llevadas a cabo por el propio personal de la fundación, sobre todo en investigaciones agrícolas y virológica. En menor grado, pero también de manera significativa (entre el 4 y el 3,6\% respectivamente), se apoyó a través de la dotación de equipos o edificios (1959, p. 31).

${ }_{7}$ El caso de la microbiología es especial, ya que si cierto es que recibió apoyos desde esta rama, también lo es que la más importante la recibió a partir de subvenciones dadas desde el Programa de Virus que veremos más adelante. 


\section{LA AGRONOMÍA}

Si bien el Programa Agrícola evolucionó considerablemente durante todo el tiempo que estuvo vigente, ${ }^{\mathbf{B}}$ podemos señalar, siguiendo principalmente a Weaver (cf. 1959 , p. 99) tres características o aspectos centrales que replican en buena medida el esquema visto en biología experimental:

(1) Fue un proyecto de ayuda y colaboración internacional. La mayoría de los proyectos de investigación y desarrollo se llevaron a cabo en México, Colombia, Chile y la India, buscando mejorar los cultivos de alimentarios de gran importancia para el país de acogida. También se apuntó a desarrollar instituciones locales y recursos, principalmente personal indígena, con el fin de que el país en cuestión pudiera hacerse cargo del proyecto en el momento oportuno.

(2) Una parte importante del programa lo ocuparon los proyectos y programas de formación de personal que, en gran medida, sirvieron a los proyectos de explotación señalados previamente, y en menor parte a formar personal clave de otros países con los que la Fundación no tenía programas operativos.

(3) Se subvencionaron universidades, escuelas de agricultura, institutos de investigación, etc., dando apoyo, sobre todo, a las investigaciones básicas en las ciencias agrícolas. Principalmente se apoyó a proyectos de investigación en fisiología vegetal, fitopatología, microbiología, bioquímica vegetal, genética etc. Todos ellos destinados a generar nuevo conocimiento científico que, finalmente, permitiesen futuros avances en agricultura.

Si bien el énfasis del proyecto estaba nuevamente en la investigación (cf. Harrar, 1956, p. 13; Rusk, 1957, p. 34; Weaver, 1959, p. 108), en este caso se trataba principalmente de una investigación con una clara propensión aplicada. Se destinaron importantes recursos a investigación básica, pero el fin último era producir, a partir del conocimiento generado, una rápida mejora en la cantidad y calidad de cultivos de alimentos básicos (Harrar, 1956, p. 18). Se esperaba con ello dar cuenta no sólo de las necesidades de una población en franco crecimiento, sino también revertir los niveles

8 El informe de J. George Harrar (1956) es un excelente resumen de los trece primeros años del Programa Agrícola de la Fundación Rockefeller. Por tratarse de un documento de primera mano, recordemos que Harrar fue el primer director del Programa Agrícola México y posteriormente director del Programa Agrícola general de la Fundación, nos basaremos en esta breve descripción del programa de agricultura en dicho documento. 
de importación de alimentos básicos, incrementando el consumo interno, pero también la exportación (Harrar, 1956, p 18-22).

Para ello, los distintos programas internacionales se sustentaron en torno a tres grandes pilares o frentes de acción estrechamente relacionados entre sí: investigación, formación, y extensión. El ejemplo más claro e importante lo encontramos en el programa mexicano, ya que se trató del programa original, erigido en modelo y patrón a seguir por el resto de sedes internacionales. Y si nos centramos en ese programa, podremos ver que, a pesar de las recomendaciones hechas por la Comisión Survet de la fundación en su informe sobre México, de los cuatro problemas (o necesidades) que se recomendaba atender, tan sólo se desarrollaron en pleno sentido dos: atender a la necesidad de desarrollar, seleccionar e introducir variedades superiores de cereales y legumbres; y controlar las plagas y enfermedades más importantes a nivel nacional. Las otras dos líneas propuestas de acción recomendadas eran: la mejora de la gestión del suelo y las prácticas de laboreo; y la introducción de mejores razas de animales de granja, principalmente de ganado (cf. Fitzgerald, 1986, p. 464).

Para tales fines, se pusieron en marcha programas y proyectos de investigación para el desarrollo de nuevas variedades por medio de la polinización abierta, sintética e hibridación (principalmente de maíz y trigo, pero también de frijol, sorgo y patata). Pero también se implementaron importantes programas para el desarrollo de fertilizantes orgánicos e inorgánicos (Harrar, 1956, p. 26), de expansión de la irrigación (Harrar, 1956, p. 18) y de control de enfermedades y plagas a través de métodos químicos, biológicos y ecológicos (cf. Harrar, 1956, p. 28).

La estrecha relación de los programas de formación con los de investigación puede darnos numerosas pistas sobre el tipo de conocimiento científico que se estaba generando en ese momento y aquél que se quería imprimir en los futuros investigadores, sobre todo investigadores locales que se esperaban que, en breve plazo de tiempo, se fueran haciendo cargo de los proyectos. Así, podemos ver cómo los principales esfuerzos en formación e investigación estuvieron fuertemente concentrados en campos de fitopatología, entomología, edafología, e hibridación vegetal (cf. Harrar, 1956, p. 6o). En algunas ocasiones también en medicina veterinaria, economía agrícola, ganadería, avicultura relacionados (cf. Harrar, 1956, p. 61). Asimismo, se aportaron numerosos fondos para becas y subvenciones para proyectos de ciencias veterinarias, virología vegetal, fisiología de animales y plantas, estadística agrícola, parasitología de plantas, genética y nematología (cf. 1956, p. 61). Incluso, se dieron fondos para investigaciones en agricultura en tierras áridas, desarrollo de recursos marinos, recursos hidráulicos, genética de poblaciones, energía solar, sociología rural y economía doméstica en las escuelas. 
Especial atención merecen los esfuerzos y los recursos que fueron destinados a apoyar y mejorar las agencias responsables de la multiplicación y distribución de semillas así como el apoyo que se facilitó a las actividades de extensión. Sin estos agentes y agencias, los esfuerzos llevados a cabo en los laboratorios y aulas hubieran tenido poco sentido. De ahí que, como parte del proyecto, en 1953 la Secretaría de Agricultura de México estableciera el Servicio de Extensión Nacional. Un servicio conformado principalmente por ingenieros agrónomos cualificados formados o apoyados por la Fundación Rockefeller (cf. Harrar, 1956, p. 29). Asimismo, desde el Programa Agrícola Mexicano se prestó especial cuidado y atención a la publicación de los resultados obtenidos en los boletines técnicos, circulares populares y publicaciones profesionales que permitieran hacer llegar la información oportuna de manera rápida y efectiva a sus principales usuarios.

\section{El Programa Virus}

Algo muy parecido encontramos en el Programa Virus (Virus Program): la tercera línea más importante del Programa de Biología Experimental. Liderado por Robert Morison, director de la Pesquisa Biológica y Médica, ${ }^{9}$ este programa tenía dos grandes ramas. Por un lado, todo un aparato de apoyos y becas a científicos y grupos de investigación de laboratorios de todo el mundo que estaban dedicados a la investigación sobre virus. Esas investigaciones iban desde el estudio de la naturaleza bioquímica, genética y estructural de las partículas constitutivas últimas de los virus, hasta las investigaciones epidemiológicas. La segunda rama del programa, mientras tanto, era de corte operativo. Se trataba de la coordinación de centros y estaciones de campo en Trinidad, Brasil, Sudáfrica, e India.

Allí se trataban - generalmente junto a instituciones locales - problemas básicos de la región pero también comunes a las cinco estaciones. Fue por ello que las investigaciones se centraron, sobre todo, en el estudio de virus transmitidos por artrópodos, que infectasen a los seres humanos. Especial énfasis se puso en la identificación de virus hasta entonces desconocidos, en los principales síntomas clínicos que solían producir, en su distribución geográfica, en las características ecológicas (precipitaciones, temperatura, grado de urbanización etc.) de los lugares en los que se presenta-

9 En 1954 se llevó a cabo una reestructuración organizacional de la Fundación Rockefeller que supuso la desaparición de la División de Ciencias Naturales, hasta entonces dirigida por Warren Weaver, y la creación de la investigación biológica y médica (biological and medical research). A partir de ese momento, y hasta 1958, Weaver sería vicepresidente para las ciencias naturales y médicas. Con esa fusión, según Robert Morison (1956, p. 44) señalaba en su primer informe anual, se intentaba responder al interés e intención de la fundación de no distinguir arbitrariamente entre genética humana y animal. 
ban, y en sus vectores biológicos: principalmente insectos, como se acaba de apuntar, pero también mamíferos y aves.

Ahora bien, a pesar de toda esta aparente diversidad disciplinaria y niveles de aproximación, lo cierto es que el programa operativo trató de centrarse en la mayoría de las ocasiones - tal y como señaló Morison (1956, p. 45) en su primer informe - en la concesión de subvenciones a investigaciones en microbiología y bioquímica de macromoléculas. Con un lenguaje y una perspectiva muy cercana a la Weaver, en este primer informe como director de la Pesquisa Biológica y Médica, Morison aventuraba:

Nuestra comprensión de la biología de los virus se enriquecerá en gran medida por los avances en el conocimiento de la estructura de proteínas y ácidos nucleídos. En años anteriores, la antigua División de Ciencias Exactas y Naturales de la Fundación contribuyó con una gran parte de sus fondos a los laboratorios que participaron en este tipo de estudios (...) La recientemente divulgación del fraccionamiento y recombinación del virus del mosaico del tabaco llevado a cabo independientemente el año pasado por dos laboratorios financiados por la Fundación, confirman la esperanza largamente sostenida de que los aspectos biológicos y médicos de las infecciones por virus encuentran explicación precisa, en última instancia, en términos físico-químicos (Morison, 1956, p. 45).

Es interesante hacer notar que estas explicaciones físico-químicas tan sólo fueron posibles tras la identificación, descripción y clasificación de virus. A pesar de haber considerado inicialmente estas fases de la ciencia como algo primitivo en la historia y práctica biológica, Weaver (1959, p. 112-3) tendrá que reconocer finalmente el grado de dependencia que el desarrollo y dirección de posteriores investigaciones tienen respecto de ellas. Otro ejemplo de cómo Weaver tuvo que reconocer este error inicial sobre el papel de las actividades de identificación, descripción y clasificación en biología lo encontramos en aquellos textos en donde habla sobre la extraordinaria importancia que tuvieron los bancos de germoplasma en los programas agrícolas (cf. 1959, p. 55). Reconocimientos estos que habría que poner junto a los de Harrar (1956) cuando reconoció la necesidad de introducir y unir en el programa agrícola distintas perspectivas, incluso sociológicas.

Llegados a este punto cabe retomar algunas de las preguntas previas aún pendientes: ¿En qué medida el Programa de Biología Experimental respondió a los objetivos y presuposiciones cognitivas y epistemológicas establecidas inicialmente, sobre todo en 1932, tanto por el consejo de la Fundación como por Warren Weaver? Pero sobre todo, ¿en qué forma medida o grado fue Weaver fiel al compromiso reduccionista al que parecía apuntar su propuesta? 


\section{EL Gompromiso REDUGGIONISTA}

Como vimos, Weaver (1959) confiaba en la posibilidad de obtener una comprensión activa y "técnica" de la compleja "realidad oculta" de los fenómenos biológicos. Para alcanzar dicho fin puso en marcha un programa que tenía como principal objetivo contribuir en la constitución de una auténtica biología científica, experimental, que permitiese dar el paso explicativo de la materia inanimada a la vida. Una biología que posibilitase superar la brecha aparentemente existente entre el mundo inanimado y el mundo vivo. Ello significó, principalmente, mostrar que todo intento por comprender, predecir y controlar un determinado proceso o fenómeno, en este caso biológico, sólo era posible a partir del desarrollo de programas que, partiendo de unidades de explicación básicas y generales, y de conceptos abstractos, permitiesen la unificación, universalización y control de los procesos y de las variables en juego. Para tal fin era preciso, según Weaver (1959, p. 48), llevar las explicaciones biológicas hasta el nivel de los átomos y de las moléculas. Es decir: era necesario poner en marcha todo un programa de transferencia y aplicación de conocimientos, metodologías, herramientas y técnicas de las ciencias físicas que estuvieran al servicio de la resolución de problemas propios de las ciencias biológicas.

Bajo esta idea gestionó y supervisó, directa e indirectamente, una gran cantidad de recursos y proyectos de muy diferentes áreas y disciplinas que, como hemos estado viendo, en último término tenían como fin la resolución de problemas y cuestiones de orden biológico. Pero la pregunta inicial sigue en el aire: ¿hasta qué punto Weaver fue fiel, se comprometió y confió realmente en la visión fisicalista, materialista y reduccionista de la biología al que el nuevo programa de biología experimental parecía apuntar? Bajo la concepción de ciencia de Weaver que hemos estado observando, las ciencias biológicas, al igual que las ciencias sociales, como disciplinas que debían dar cuenta de problemas de complejidad organizada, no podían escapar de las explicaciones reduccionistas. El lenguaje lógico y matemático, la medición, la relación y el control de variables, debían ocupar un lugar central en esa nueva biología que intentaba poner en marcha. Ahora bien, ¿de qué tipo de reduccionismo estamos hablando?

En primer lugar, de un reduccionismo ontológico o constitutivo. Weaver vendría a sostener, en los mismos términos en que Dobzhansky (1983, p. 23), Ayala (1983, p. 11) y Mayr (1988, p.11) definen esta postura, que todo fenómeno o entidad biológica es, finalmente, un compuesto complejo de fenómenos y entidades físico - químicas (átomos y moléculas finalmente) sometidos a la legalidad física que rige sus componentes (cf. Caponi, 2004, p. 37). De ahí, la necesidad de desarrollar y llevar al terreno de la biología, las metodologías y herramientas de investigación, así como el conocimiento, de las ciencias físicas. Weaver (1959) era consciente de las limitaciones aún inheren- 
tes de la física de su época, de su coyuntural incapacidad para dar cuenta de todos los fenómenos biológicos, pero confiaba en que era sólo eso: una cuestión coyuntural y transitoria. Para Weaver (1959, p. 48), sin embargo, el verdadero problema no estaba del lado de la física, sino del lado de la biología. O mejor dicho: del lado de biólogos y no del lado de los físicos.

Weaver (1959, p. 50) estaba convencido que a partir de la física ya existente era posible hacer grandes avances en el terreno de la explicación biológica. Si aun no se había avanzado demasiado en esa dirección era porque los biólogos no habían sabido aprovechar todo el arsenal conceptual e instrumental que la química y la física ponía a su disposición. Siguiendo la distinción propuesta por Elliot Sober (1993, p. 25), el programa de biología experimental impulsado por Weaver suponía una explicabilidad-enla-práctica de lo biológico por lo físico, y no una mera explicabilidad-en-principio que dejase todo el asunto librado a los desarrollos futuros de la física y no a los esfuerzos de los propios biólogos (cf. Caponi, 2004, p. 38-9). El desafío, de todos modos, era muy grande. Weaver (1959, p. 37) lo sabía y reconocía que, en 1959, los resultados obtenidos por el desarrollo del programa, sólo aludían a la primera de tres preguntas a las que, según George Wald (1958), debía responderse en el estudio de fenómeno biológico:

(1) ¿Cómo funciona (mecanismo)?;

(2) ¿Qué hace para el organismo (adaptación)?; y

(3) ¿Cómo llegó a darse (evolución)?

Weaver (1959) sabía, en efecto, que los apoyos de la Fundación Rockefeller se habían centrado, prácticamente desde el inicio de su dirección, en el desarrollo de proyectos de investigación dirigidos a dar respuesta a la primera de las preguntas indicadas por Wald. Pero, ¿significa eso que todos los proyectos respondieron a esta óptica o tuvieron como principal objetivo esta perspectiva? A partir de lo que hemos estado viendo la respuesta ha de ser negativa. En primer lugar no podemos ignorar que el mismo Weaver señaló y defendió durante los veintitrés años que estuvo al frente de la División de Ciencias Naturales que los investigadores, pero sobre todo los responsables de cada proyecto de investigación, debían sentirse libres para tomar decisiones o redirigir los proyectos en función de las oportunidades que fueran apareciendo (cf. 1959, p. 7). Pero, más claras que las afirmaciones o proclamas de Weaver, son las cifras y los datos existentes en torno a la diversidad de proyectos que bajo su dirección fueron apoyados desde la Fundación.

Hubo un interés por desarrollar una nueva forma de entender las ciencias de la vida; pero ello no significó dejar de apoyar otras formas, programas y niveles de investigación. La visión pragmática y utilitarista de la ciencia que Weaver patrocinaba se 
llevaba muy bien con las tesis fisicalistas y reduccionistas. Éstas eran afines con el desarrollo de programas de investigación que pudiesen redundar en avances relativos al control de variables y al progreso en al ámbito de las predicciones, y que también pudiesen conducirnos hacia explicaciones biológicas cuya elegancia y generalidad fuese semejante a la elegancia y generalidad de las explicaciones físicas. Pero eso no llegó a impedir que la fundación apoyase el desarrollo de programas que obedecían a otras perspectivas. Y las propias posiciones epistemológicas de Weaver podían justificar ese pluralismo.

El reconocimiento de las limitaciones de la ciencia, ${ }^{10}$ así como del desacuerdo existente entre los mismos científicos sobre la relación que hay entre el pensamiento científico y la realidad, y sobre la naturaleza y el significado de la realidad misma, permitieron que Weaver $(1957 ; 1964$ b) reconociese, en numerosas ocasiones, la legitimidad de programas de investigación no-reduccionistas que, sin atentar contra el fisicalismo, permitían atender cuestiones que envolvían fenómenos cuyas propiedades podríamos caracterizar como altamente sobrevinientes (cf. Caponi, 2013, p. 5). Esos otros programas, podían permitir superar las limitaciones, teóricas y hasta presupuestales, de los programas reduccionistas; e incluso hasta podían servir para poner en evidencia algunos errores a los que podía conducirnos la perspectiva reduccionista debido a esas limitaciones coyunturales, que ciertamente la aquejaban. La epistemología de Weaver era demasiado pragmática como para desconocer esa posibilidad.

Para Weaver (1959), la explicación última de todo fenómeno biológico estaba en el nivel de los elementos físico-químicos que componían a las estructuras orgánicas. Y era ahí que la biología experimental debía llegar. Pero ese empeño reduccionista podía ser coyunturalmente, o tácticamente, dejado de lado: esperando que otros enfoques finalmente nos permitiesen encontrar la brecha por la cual descender hacía la infraestructura física del fenómeno biológico en estudio. Y son los científicos los que deben saber decidir cuándo parar momentáneamente el proceso de abstracción, de generalización, y de reducción, y cuándo retomarlo. La epistemología sólo nos marca la meta final y nos advierte que ese objetivo puede no ser alcanzado en línea recta. Usando metáforas del propio Weaver, podemos decir que él sabía que la explicación vertical podía ser el resultado final de un descenso zigzagueante en el que, en ocasiones, la dirección seguida puede llegar a ser casi horizontal.

10 Sobre todo aquellas relacionadas con la caída de la antigua idea de inevitabilidad y determinismo, con la nueva imagen de las matemáticas como una disciplina cercana al arte (naturaleza más creativa que descubridora) y de la lógica como algo débil e incompleta, y con el reconocimiento de que la idea de verdad o de ciencia objetiva son sólo fruto de nuestra voluntad. 
De hecho, los proyectos del Programa de Biología Experimental fueron desarrollados en muy distintos niveles de complejidad: matemático, atómico, molecular, genético, citológico, embriológico y ecológico. Aunque Weaver nunca dejó de insistir en su identificación entre explicación científica y reducción. El control de la naturaleza siempre fue el principal valor cognitivo del Programa de Biología Experimental; $y$ para Weaver existía una relación directa entre la simplicidad y control. Cuanto mayor fuese nuestra capacidad para llevar la explicación de los fenómenos hasta unidades más simples y básicas, mayor será nuestra capacidad para controlar los procesos. Sin embargo, esta es sólo una de las muchas maneras de controlar los fenómenos (cf. Caponi, 2004, p. 46-8); y, al privilegiarla, Weaver, y la Rockefeller Foundation, marcaron vectores de progreso para todas las ciencias biológicas que están lejos de ser exigencias de la pura razón.

\section{UNA ÚLTIMA GONSIDERAGIÓN}

El privilegio que hoy tiene la biología molecular dentro del universo de las ciencias de la vida, es, en gran parte, el resultado de esas opciones epistemológicas reivindicadas por Weaver y patrocinadas por la Fundación Rockefeller. Y, si ya no cabe impugnar ese status quo, por lo menos se puede ponerlo en perspectiva histórica: se puede reconocer que el régimen epistémico que hoy rige los destinos de las ciencias de la vida se impuso en virtud de elecciones que no obedecían a las exigencias teóricas y metodológicas de toda biología posible. Más aún: en gran parte, fueron esas mismas opciones las que consagraron las exigencias metodológicas que hoy entronizan a la biología molecular y la erigen en vector de progreso de todo ese dominio de las ciencias de la vida que Mayr (1961) llamó "biología funcional”. Weaver, y sobre todo la Fundación Rockefeller, lograron imponer un modo de hacer biología y consiguieron que otros modos posibles de hacerla, también científicamente legítimos y potencialmente fértiles en términos cognitivos, quedasen relegados o eclipsados, y hasta fuesen olvidados. No es malo saberlo.e

Agradecimientos. Este estudio forma parte del proyecto de investigación titulado "La influencia de la concepción de ciencia de la Fundación Rockefeller en el desarrollo de la investigación biológica y agrícola mexicana” [número 168062] financiado por CONACYT en su convocatoria de 2011 de Investigación Básica SEP-CONACYT, Modalidad Joven Investigador $\left(\mathrm{J}_{2}\right)$. 


\title{
Francisco Javier Serrano-Bosquet \\ Departamento de Filosofía y Ética, \\ Tecnológico de Monterrey.
}

Sistema Nacional de Investigadores, México.

fjavierserrano@itesm.mx

Gustavo Caponi

Departamento de Filosofia,

Universidade Federal de Santa Catarina.

CNPq, Brasil.

gustavoandrescaponi@gmail.com

\section{Warren Weaver and the experimental Biology Program of the Rockefeller Foundation}

\begin{abstract}
The aim of this article is to uncover the main cognitive and epistemological values that influenced Warren Weaver in starting the Experimental Biology Program, a program carried out from the time that he became president of the Natural Sciences Division of the Rockefeller Foundation, and which significantly marked and conditioned the subsequent development of biological research. To this end, we first describe the arrival of Warren Weaver at the Rockefeller Foundation, and the reasons for which the Board of this Foundation, between 1932 and 1933, decided to prioritize biomedical research, and the manner in which they did so. Then, secondly, in the largest and most important part of the article, we will present some of the most significant elements of Weaver's epistemological and cognitive perspective. Finally, we will show how this perspective, developed in connection with the Experimental Biology Program, interacted with the reductionist view of biology to which the program seemed to point.
\end{abstract}

KEYwords • Weaver. Rockefeller Foundation. Experimental Biology. Molecular Biology. Reductionism. Cognitive values. Epistemology.

\section{REFERENGIAS BIBLIOGRÁFICAS}

Ayala, F. Introducción. In: Ayala, F. \& Dobzhansky, T. (Ed.). Estudios sobre la filosofía de la biología. Barcelona: Ariel, 1983. p. 9-20.

Ayala, F. \& Dobzhansky, T. (Ed.). Estudios sobre la filosofía de la biología. Barcelona: Ariel, 1983.

CAPONI, G. El reduccionismo en la biología contemporánea. Signos Filosóficos, 6, 12, p. 33-62, 2004.

. Niveles de sobreviniencia y expectativas reduccionistas en biología. Contrastes, suplemento, 18, p. $27-4,0,2013$.

Dobzhansky, T. El azary la creatividad en la evolución. In: Ayala, F. \& Dobzhansky, T. (Ed.). Estudios sobre la filosofía de la biología. Barcelona: Ariel, 1983. p. 392-430. 
Engstrom, A. \& Finean, J. Bioloffifal ultrastructure. New York: Academic Press, $195^{8}$.

FitzGerald, D. Exporting american agriculture: the Rockefeller Foundation in Mexico, 1943-1953. Social Studies of Science, 16, 3, p. 457-83, 1986.

GLAss, B. The Rockefeller Foundation: Warren Weaver and the launching of molecular biology. The Quarterly Review of Biology, 66, p. 3०3-8, 1991.

HarRar, J. The agricultural program of the Rockefeller Foundation. New York: Guide/Kalkhoff/Burn, 1956.

Lacey, H. Valores e atividade científica 1. São Paulo: Associação Filosófica Scientiae Studia/Editora 34, 2008.

MAYr, E. Cause and effect in biology. Science, 134, p. 1501-6, 1961. Toward a new philosophy of biology. Cambridge: Harvard University Press, 1988.

Morison, R. S. Biological and medical research. The Rockefeller Foundation Annual Report, 1955. New York: Rockefeller Foundation, p. 44,-52, 1956.

Polanyi, M. Personal knowledge. Chicago: University of Chicago Press, $195^{8}$.

ReEs, M. Warren Weaver 1894-1978: a biographical memoir. Washington: National Academy of Sciences, 1987 .

Rusk, D. The president's review. The Rockefeller Foundation Annual Report, 1956. New York: Rockefeller Foundation, p. 1-69, 1957.

Introduction to Weaver, W. "A quarter century in the natural sciences". The Rockefeller Foundation Annual Report, 1958. New York: Rockefeller Foundation, p. 3-6, 1959.

Soвer, E. Philosophy of biology. Oxford: Oxford University Press, 1993.

WALD, G. Innovation in biology. Scientific American, 199, 3, p. 100-2, $195^{8}$.

WeAVER, W. Science and imagination. The Scientific Monthly, 29, 5, p. 4.25-34, 1929.

. The reign of probability. The Scientific Monthly, 31, 5, p. 457-66, 1930.

. Science and complexity. American Scientist, 36, 4, p. 536-44, 1948.

. Science and the citizen. Science, 126, p. 1225-9, 1957 .

. A quarter century in the natural sciences. The Rockefeller Foundation Annual Report, 1958. New York: Rockefeller Foundation, p. 7-122, 1959.

. The imperfections of science. Proceedings of the American Philosophical Society, 104, 5, p. 419-28, 1960.

Why science is important? Nutrition Reviews, 19, 3, p. 65-8, 1961a.

. A quarter century in the natural sciences. Public Health Reports, 76, 1, p. 57-65, 1961b.

. Scientific explanation. Science (new series), 143, p. 1297-300, 1964a.

. Max Mason 1877-1961: a biographical memoir. Washington: National Academy of Sciences, 1964b.

. Confessions of a scientist-humanist. Saturday Review, 28, p. 12-5, 1966. 